\title{
IMMUNE SURVEILLANCE IN THE SKIN: MECHANISMS AND CLINICAL CONSEQUENCES
}

\section{Thomas S. Kupper and Robert C. Fuhlbrigge}

The skin, as the primary interface between the body and the environment, provides the first line of defence against a broad array of microbial pathogens and trauma. In addition to its properties as a physical barrier, the skin has many active defence mechanisms. In this review, we discuss the interaction between the innate and adaptive immune systems in the skin as a model for immune function at epithelial-cell interfaces with the environment. How these mechanisms account for the robust nature of cutaneous immune surveillance and how their dysregulation drives the pathogenesis of inflammatory skin disorders and skin-based tumours are the subjects of this review.

Department of Dermatology, Brigham and Women's Hospital, Harvard Institutes of Medicine, 77 Avenue Louis Pasteur, Boston, Massachusetts 02115, USA. Correspondence to R.C.F. e-mail:rfuhlbrigge@ partners.org doi:10.1038/nri1310
We live in a hostile environment, surrounded by microbial pathogens and subject to a range of physical and chemical insults. To survive in this environment, vertebrates have evolved complex immune systems. A key element of this defence is the deployment of rapid response elements at the most probable sites of attack, which are the epithelial-cell boundaries between the body and the environment in the skin, gut and lungs.

As the body's largest and most exposed interface with the environment, the skin has a central role in host defence. Before the relatively recent discovery of the immunological defences of skin, the cutaneous interface was viewed as a passive barrier between the host and the hostile environment. In the past few decades, however, it has become apparent that the mechanical aspects of epidermal defence are reinforced by a versatile and robust system of immune surveillance ${ }^{1}$ (FIG. 1). The crucial role of immune surveillance in maintaining homeostasis is evident from the marked increase in the frequency and severity of cutaneous malignancies and infections when immune function is limited, for example in patients with genetic and acquired immunodeficiency disorders and in those receiving immunosuppressive therapy after organ transplantation ${ }^{2,3}$. The regulation of skin defence mechanisms is also crucial, as inappropriate or misdirected immune activity is implicated in the pathogenesis of a large variety of acquired inflammatory skin disorders, including psoriasis, atopic and allergic contact dermatitis, lichen planus, alopecia areata and vitiligo ${ }^{4-10}$. The role of immune dysfunction in these conditions is emphasized by their response to immunosuppressive therapeutic interventions $s^{11-14}$.

Understanding the mechanisms of immune surveillance in the skin and tissue-specific immune responses also has important implications for the rational design of vaccines. To promote protective immunity, an immunization protocol must elicit not only an antigenspecific immune response, but also an effective memory response that will provide long-lived protection at the most probable sites of invasion. This applies equally to immunization against infectious organisms, which in most cases invade through the skin or the epithelia of the gastrointestinal or respiratory systems, and to the elicitation of immune responses against tumours. As we discuss, the route and means of adjuvant stimulation that is used can affect the effectiveness and utility of specific vaccine strategies.

In this review, we discuss these issues in the context of recent advances in our understanding of cutaneous immune mechanisms, highlighting the interaction of 
innate and adaptive immune systems in the induction and maintenance of effective cutaneous immune surveillance.

\section{Innate immune surveillance}

Central to our model of cutaneous immune surveillance are the cells resident in the skin, which function as sentinels for DANGER SIGNALS, including invasion by microorganisms. Keratinocytes and LANGERHANS CELLS in the epidermis, as well as dermal mast cells, dendritic

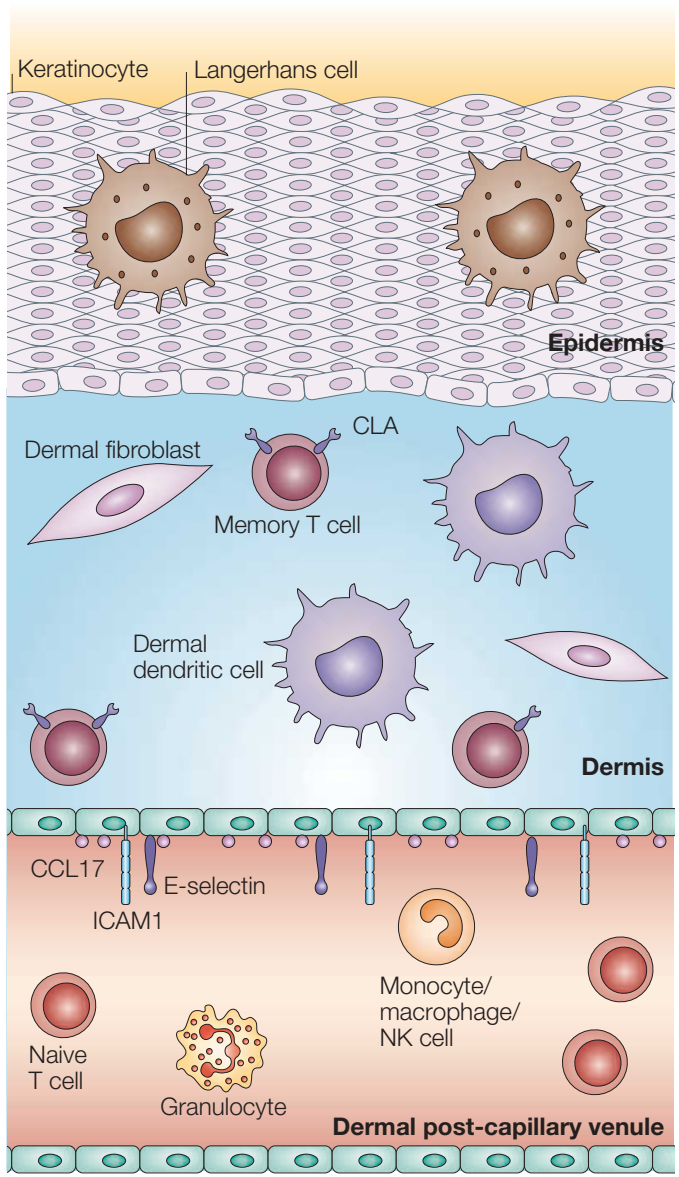

Figure 1 | Immune-response elements in non-inflamed skin. Human skin is composed of three distinct compartments relevant to its immune functions. First, the epidermis is composed of keratinized epithelial cells and functions as both a physical barrier and an early warning system. Immune cells resident in the epidermis include specialized dendritic cells (DCs) known as Langerhans cells and intraepithelial lymphocytes. Second, the dermis is mainly composed of connective tissue produced by dermal fibroblasts. Immune system cells resident in non-inflamed dermis include dermal DCs, mast cells and a small number of cutaneous lymphocyte antigen (CLA)-positive memory T cells. Third, dermal post-capillary venules constitutively express low levels of E-selectin, CC-chemokine ligand 17 (CCL17) and intercellular adhesion molecule 1 (ICAM1). These support the margination and baseline emigration of $\mathrm{CLA}^{+}$memory T cells into non-inflamed skin. CLA ${ }^{-} \mathrm{T}$ cells, including both naive cells and memory/effector cells that are targeted to other tissues, as well as granulocytes and other immune cells, lack the appropriate receptors to attach to dermal vessels and emigrate into non-inflamed skin. cells (DCs) and macrophages, provide an early warning system by releasing stored and inducible ANTIMICROBIAL PEPTIDES, chemotactic proteins and cytokines ${ }^{15-19}$ (FIG. 2). Keratinocyes are important and often under-appreciated participants in cutaneous immune responses. They produce large quantities of interleukin-1 $\alpha$ (IL- $1 \alpha$ ), tumour-necrosis factor (TNF) and antimicrobial peptides such as $\beta$-defensins in response to various stimuli, including kinetic and thermal trauma, ultraviolet radiation, cytokines and neuropeptides ${ }^{15,20-22}$. IL-1 $\alpha$ (and IL-1 $\beta$ from epidermal Langerhans cells), in turn, acts as a potent stimulator of local immune function ${ }^{23}$. Keratinocytes also produce a large number of chemokines and other immunoregulatory cytokines in response to stimulation ${ }^{16,24-27}$. These products have various important effects on resident innate immune cells in the skin, such as mast cells, DCs and macrophages, resulting in the upregulation of expression of other inducible mediators and recruitment of additional immune cells from the blood ${ }^{28}$. The induction of local inflammation through IL-1, however, depends on the balance of agonists (IL- $1 \alpha$, IL- $1 \beta$, caspase- 1 and IL- 1 receptor 1; IL-1R1) and antagonists (IL-1Ra and IL-1R2) that are active in this pathway ${ }^{15,16,23}$. Each of these molecules can be produced by keratinocytes under various conditions, as well as by other cells that are resident in the skin, making it difficult to predict the effects of specific interventions. New members of the IL-1 family continue to be identified, adding to the complexity of regulation of cutaneous inflammation ${ }^{29}$.

Both the epithelial barrier cells and resident innate immune cells in the skin express pattern-recognition receptors that recognize specific pathogen components and can trigger downstream activation cascades. An important subset of these receptors belong to the Tolllike receptor (TLR) family ${ }^{30-33}$, which bind pathogenassociated molecular pattern molecules such as lipopolysaccharide ${ }^{34}$, bacterial lipoproteins $s^{35,36}$, flagellin ${ }^{37}$, yeast mannans ${ }^{38}$ and unmethylated CpG DNA motifs ${ }^{39,40}$. TLR expression is variable and might identify subsets of innate immune cells, such as DCs, with specific functions ${ }^{4-43}$. DC activation through TLRs results in increased production of pro-inflammatory cytokines and antimicrobial peptides, increased nitric oxide synthesis and enhanced bacterial killing, as well as increased antigen presentation ${ }^{30}$. The binding of TLR ligands is associated with the recruitment of intracellular adaptor proteins similar to those used by IL-1R and subsequent activation of the JUN N-terminal kinase (JNK) and nuclear factor- $\kappa \mathrm{B}(\mathrm{NF}-\kappa \mathrm{B})$ signalling pathways $\mathrm{s}^{30}$. The NF- $\kappa \mathrm{B}$ signalling pathway is seen as a key link between the innate and adaptive immune systems. In the skin, NF- $\mathrm{KB}$ regulates the expression of numerous genes that are involved in the initiation of the inflammatory response, including adhesion molecules, chemokines and cytokines (such as IL-1 and TNF), matrix metalloproteases, nitric oxide synthase and enzymes that control PROSTANOID synthesis ${ }^{44}$. Beyond the direct effects of these compounds on pathogens and abnormal cells, products of the innate immune response direct the recruitment of additional leukocytes to the site 
of activation. In humans, genes regulated by NF- $\mathrm{B}$ include the endothelial adhesion molecules E-selectin and P-selectin, intercellular adhesion molecule 1 (ICAM1), vascular cell-adhesion molecule 1 (VCAM1), and various chemokines and cytokines ${ }^{45}$. Collectively, these molecules are considered to be both necessary and sufficient for initiation of the leukocyte adhesion-extravasation cascade that recruits circulating leukocytes from the periphery ${ }^{46}$. These include antigen

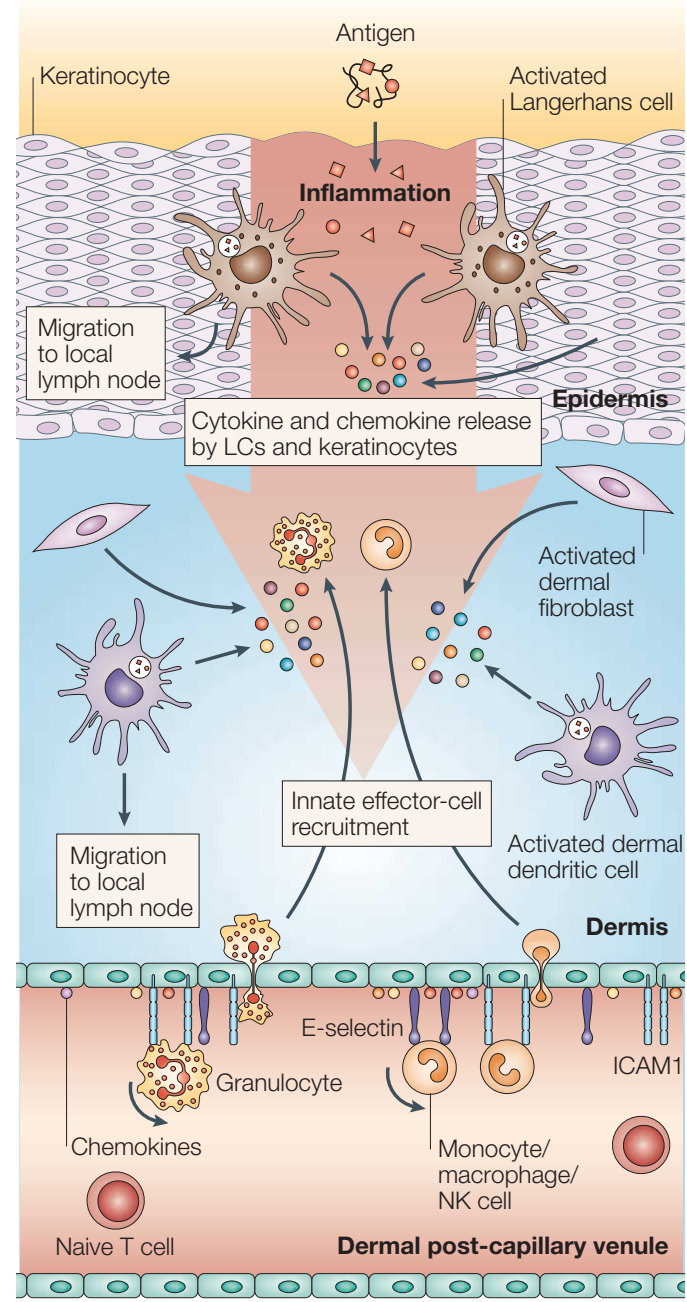

Figure 2 | Innate immune mechanisms in the skin. Epithelial-cell injury or pathogen invasion leads to the release of primary cytokines and the activation of both skin cells (keratinocytes and fibroblasts) and resident innate immune cells (Langerhans cells (LCs), dermal dendritic cells (DCs) and mast cells), stimulating downstream activation cascades. Activated Langerhans cells and dermal DCs are stimulated to mature and emigrate from the tissue to the draining lymph node, carrying antigen for presentation to naive and memory $T$ cells. The cytokines and chemokines produced in response to this activation cascade act on the local endothelia through nuclear factor- $\mathrm{\kappa B}$ (NF-kB)-mediated pathways to upregulate the expression of adhesion molecules, including E-selectin, P-selectin and intercellular adhesion molecule 1 (ICAM1), and direct the recruitment of additional innate immune components according to the specific signals that are generated - for example, neutrophils, eosinophils and natural killer (NK) cells. CCL17, CC-chemokine ligand 17. non-specific leukocytes, such as neutrophils and natural killer cells, as well as key components of the adaptive immune system, such as effector T cells (FIG. 3).

Mast cells are another crucial component of the cutaneous immune response apparatus. Mast cells have been shown to release different patterns of cytokines and bioactive compounds, including leukotrienes, IL-1 $\beta$, IL-4, IL-5, IL-6, IL-13, TNF and granulocyte-macrophage colony-stimulating factor (GM-CSF), in response to various TLR ligands $s^{4-49}$. These and other mast-cell products have an important role in both the initiation and modulation of innate immune responses and the generation of adaptive immune responses.

\section{Adaptive immune surveillance}

The adaptive immune system, based on T cells and B cells that express antigen-specific receptors, provides vertebrate organisms with a broader and more flexible repertoire of responses to pathogens, and a means for providing memory of past encounters. Adaptive immune surveillance addresses the logistical challenge faced by the immune system in getting the right $\mathrm{T}$ cell to the right place at the right time. At the skin interface, this process can be viewed as operating at three levels, which we term primary, secondary and tertiary immune surveillance (FIG. 4). Primary immune surveillance incorporates the mechanisms for bringing environmental antigens that are encountered in the skin, professional antigen-presenting cells (APCs) and naive T cells together in the specialized microenvironment of skin-draining lymph nodes. Secondary immune surveillance, in turn, involves the production and distribution of antigen-specific effector memory $\mathrm{T}$ cells expressing homing receptors that direct their migration to the tissue where antigen was encountered. Tertiary immune surveillance encompasses the long-term elements of the acquired immune response, including the production of central memory and effector cells that are potentially directed to tissues other than the site of primary exposure. Each of these modes of immune surveillance is a strategy used by the immune system to improve the odds that each $\mathrm{T}$ cell will find the antigen for which its $\mathrm{T}$-cell receptor (TCRs) is specific and develop effective responses: first, by increasing the efficiency with which naive $\mathrm{T}$ cells are exposed to antigens; second, by targeting the effector response to the most appropriate tissue site; and third, by expanding coverage to other tissues.

Primary immune surveillance. Activated DCs, whether derived from epidermal Langerhans cells or dermal DCs ${ }^{50,51}$, are professional APCs with the capacity to present antigens efficiently and to affect the maturation of naive T cells to a memory/effector phenotype ${ }^{52}$. At sites of injury or pathogen invasion in the skin, these cells become activated through innate mechanisms, including pattern-recognition receptors (such as TLRs) and exposure to the pro-inflammatory cytokines (such as IL-1 and TNF) that are released in response to tissue injury or infection. Activated APCs rapidly engulf foreign particles and undergo maturation as they emigrate through the afferent lymphatics to the 
local skin-draining lymph nodes ${ }^{52,53}$. This maturation process enhances antigen processing and upregulates the expression of MHC molecules and co-stimulatory molecules, including CD80 and CD86 (REF. 54).

The function of the local draining lymph nodes is to promote frequent and supervised contact between antigens that are derived from a specific segment of

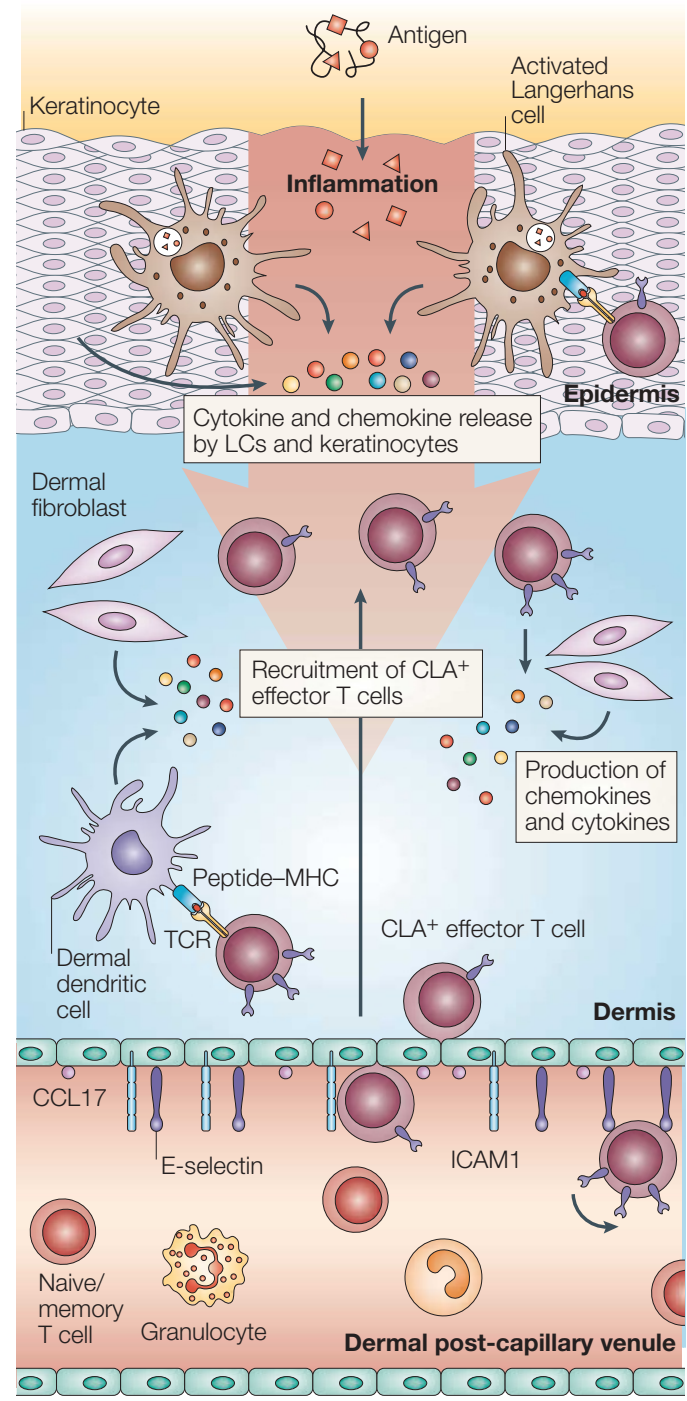

Figure 3 | Adaptive immune responses in the skin. Circulating cutaneous lymphocyte antigen (CLA)-positive $T$ cells represent a library of memory $T$ cells with $T$-cell receptors (TCRs) specific for antigens previously encountered in the skin. Cytokines released by keratinocytes, fibroblasts and resident antigen-presenting cells stimulate the upregulation of expression of E-selectin and intercellular adhesion molecule 1

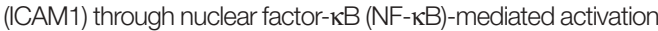
pathways. Production and presentation of T-cell-specific chemokines, such as CC-chemokine ligand 17 (CCL17), CCL22 and CCL27, on the local endothelium results in the recruitment of $\mathrm{CLA}^{+} \mathrm{T}$ cells in an antigen non-specific manner. $T$ cells entering the tissue that encounter their specific antigen presented by local macrophages or dendritic cells will be activated to proliferate and carry out their specific functions. Those that do not encounter their cognate antigen, which might be most of the cells that are recruited, will enter the lymphatics and return to the general circulation. LC, Langerhans cell. the skin (carried by DCs that have migrated through afferent lymphatics) and the adaptive immune system ( $\mathrm{T}$ cells entering the lymph node through high endothelial venules). Naive T cells that encounter their cognate antigen presented by an activated and mature DC will undergo proliferation and clonal expansion, produce autocrine growth factors and differentiate into memory/effector T cells.

Secondary immune surveillance. When an antigen is encountered in a specific tissue, such as the skin, the activation of T cells in the local draining lymph nodes results in the production of antigen-specific effector cells that express homing receptors for that site. In this way, the immune response is preferentially targeted back to the site of the initial infection or stimulation. $T$ cells recruited to sites of inflammation in the skin will encounter a range of inflammatory mediators triggered by innate immune mechanisms, as well as activated dermal DCs and inflammatory dendritic epidermal cells (IDECs) that can present antigen and provide co-stimulatory signals to $\mathrm{T}$ cells that express appropriate counter-receptors ${ }^{55,56}$.

With regard to the recruitment of T cells to the skin, the earliest step in this process is the tethering and rolling of T cells on E-selectin and/or P-selectin expressed by dermal post-capillary venules. Skin-homing T cells can be identified by expression of the cell-surface carbohydrate epitope cutaneous lymphocyte antigen (CLA), which binds E-selectin. CLA is expressed by $\sim 30 \%$ of circulating memory $\mathrm{T}$ cells and is virtually absent on naive $\mathrm{T}$ cells ${ }^{57}$. T cells found in inflammatory skin lesions are mainly $\mathrm{CD} 45 \mathrm{RO}^{+} \mathrm{CLA}^{+}$, whereas few $\mathrm{T}$ cells that accumulate in inflammatory sites other than the skin express CLA ${ }^{57,58}$. CLA is reproducibly found on most $T$ cells present in cutaneous lymphocytic infiltrates of almost all skin diseases, including psoriasis, atopic dermatitis, allergic contact dermatitis, erythema multiforme, cutaneous GRAFT-VERSUS-HOST DISEASE (GVHD) and cutaneous T-cell lymphoma (CTCL) ${ }^{57-64}$. In biopsies of CTCL, both malignant $\mathrm{T}$ cells and those that respond to the presence of tumour cells in the skin are CLA ${ }^{+}$. CLA also seems to be a good marker of malignant CTCL cells in the peripheral blood of some patients with Sezary syndrome ${ }^{65}$.

The factors that induce CLA expression by $\mathrm{T}$ cells are less well understood, but seem to be related to the specialized environments present in secondary lymphoid tissue. That is, the microenvironment in skin-draining lymph nodes promotes the expression of CLA by newly activated effector T cells, whereas that of Peyer's patches, for example, favours the expression of $\alpha_{4} \beta_{7}$ (a guthoming receptor) by new effector T cells ${ }^{66-68}$. A large volume of circumstantial evidence supports this model. For example, circulating memory $\mathrm{T}$ cells specific for nickel or house-dust mite in allergic or atopic individuals, respectively, express high levels of CLA ${ }^{62}$, presumably because these antigens were encountered through the skin. Similarly, circulating $\mathrm{CD}^{+}$effector T cells specific for skin-associated viruses express CLA, whereas those specific for non-cutaneous viruses do not ${ }^{69}$. By contrast, 


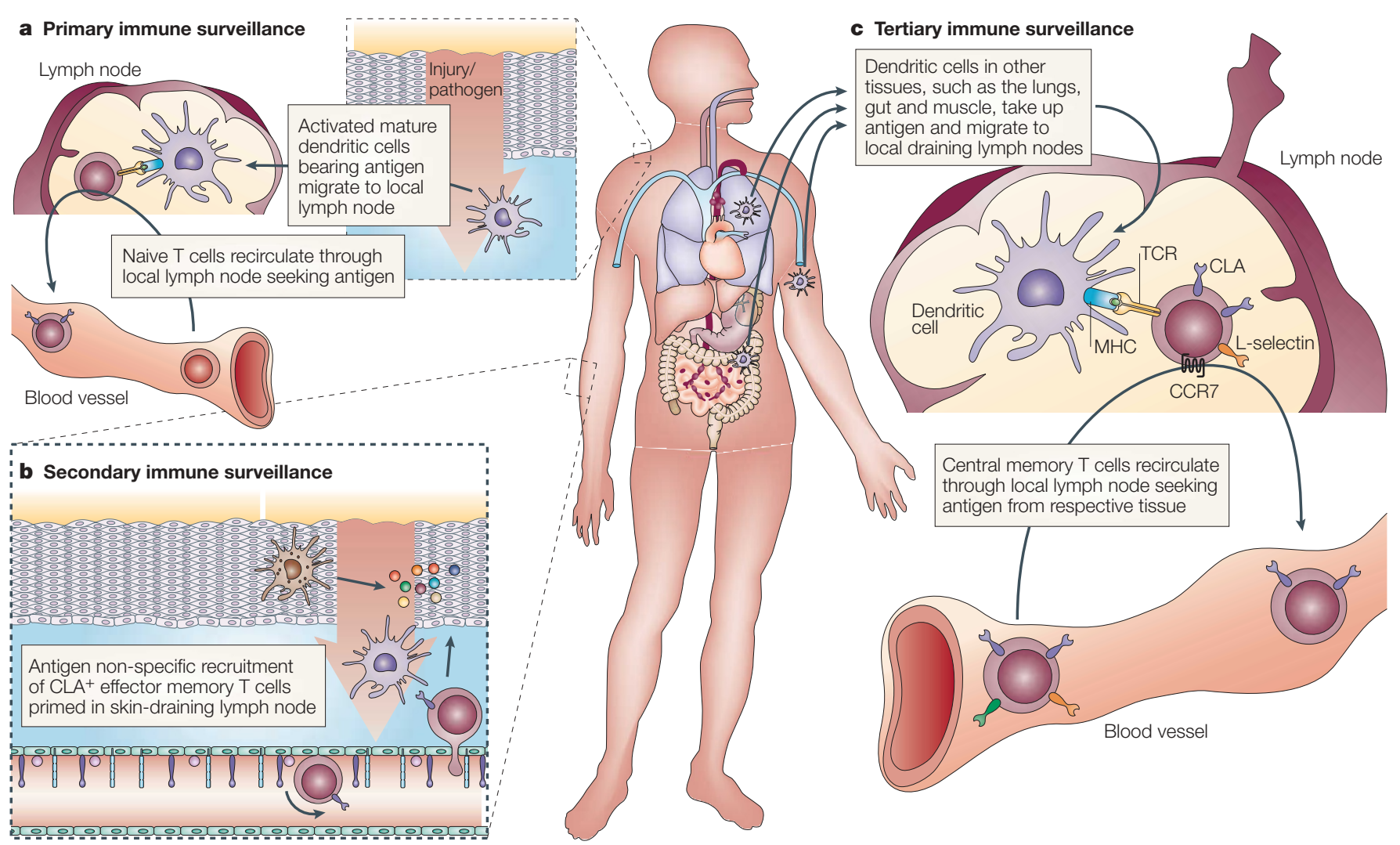

Figure 4 | Immune-surveillance mechanisms in the skin. a | Primary immune surveillance is the process by which the innate immune response ensures the effective engagement of the adaptive immune response. Antigens encountered in the skin are carried by activated dendritic cells through the afferent lymphatics to the draining lymph nodes, and presented to naive and central memory $T$ cells circulating through the node. This increases the likelihood of encountering $T$ cells that express the appropriate T-cell receptor (TCR). T cells that encounter their cognate antigen proliferate and differentiate into effector cells expressing homing receptors for the tissue served by that node. b | Secondary immune surveillance provides a mechanism for ensuring rapid and effective local adaptive immune responses to previously encountered antigens. Tissue inflammation results in the upregulation of expression of adhesion molecules and presentation of specific chemokines on the local endothelium. Effector memory $T$ cells that express the appropriate counter-receptors are recruited in an antigen non-specific manner. Those cells that encounter their cognate antigen presented by local antigen-presenting cells (APCs) participate in the local inflammatory response, whereas those that do not return to the general circulation. c | Tertiary immune surveillance represents a mechanism by which the immune system can hedge its bets, providing enhanced adaptive immune responses to antigens encountered in tissues distinct from those in which they were previously encountered. Central memory $T$ cells produced in skin-draining lymph nodes express L-selectin and CC-chemokine receptor 7 (CCR7), which allows them to recirculate through lymph nodes throughout the body, where they can provide enhanced responses to antigen encountered through a different environmental interface. CLA, cutaneous lymphocyte antigen.

T cells specific for rotavirus are $\mathrm{CLA}^{-}$, but express high levels of $\alpha_{4} \beta_{7}$ (REF. 70) as the immune system encounters this virus through the gut. More recently, mouse studies indicate that DCs derived from Peyer's patches can preferentially induce the expression of $\alpha_{4} \beta_{7}$ by newly generated effector cells in vitro ${ }^{67,68}$.

Studies of CLA induction in vitro have indicated that expression is enhanced by CD3 activation in the presence of IL-12 and is not restricted to functional and phenotypic T-cell subsets ${ }^{71,72}$. However, the factors that regulate the induction of expression in vivo and the maintenance of expression by resting circulating cells have not been determined.

Although CLA and $\alpha_{4} \beta_{7}$ mediate specific tethering and rolling steps in distinct tissue vascular beds, the activation of these rolling cells also proceeds in a tissuespecific manner. Several chemokines and their receptors are associated with skin-homing $\mathrm{T}$ cells ${ }^{73-75}$, including CC-chemokine receptor 4 (CCR4) and its ligands CCL17 (thymus and activation-regulated chemokine, TARC) and CCL22 (macrophage-derived chemokine, MDC). Constitutive and inducible expression of CCL17 on the luminal aspect of post-capillary venules in the skin has been shown, and CLA ${ }^{+}$cells typically co-express CCR4. CCR4-CCL17 interactions can lead to the arrest of rolling $\mathrm{T}$ cells if they are provided an integrin ligand. CCL27 (cutaneous T-cell-attracting chemokine, CTACK) has also been implicated in skin homing. This chemokine, preferentially produced by epidermal keratinocytes, binds to CCR10 and is chemotactic for $\mathrm{T}$ cells in vitro ${ }^{76-78}$. CCR10 is expressed by a subset of $\mathrm{CLA}^{+} \mathrm{T}$ cells only, and its role in inducing the arrest of $\mathrm{T}$ cells on post-capillary venules in the skin has not been shown. Other work indicates that CCR6 might be 
important for skin homing ${ }^{79}$, though the expression of this chemokine receptor is more variable. In most situations, it seems that skin-homing memory cells that express CLA, CCR4 and leukocyte function-associated antigen 1 (LFA1) accumulate in the skin, where E-selectin, CCL17 and ICAM1 are constitutively and inducibly expressed on post-capillary venules. What role other receptor-ligand pairs will have in specific conditions remains to be determined. Cytokines produced by $\mathrm{T}$ cells that are recruited to sites of inflammation can influence the content of the ongoing infiltrate by modifying the balance of chemokines produced. For example, interferon- $\gamma($ IFN- $\gamma$ ) can induce keratinocytes to produce a range of products, including CXCL10 (IFNinducible protein 10, IP-10), CXCL9 (monokine induced by IFN- $\gamma$, MIG) and CXCL11 (IFN-inducible T-cell $\alpha$-chemoattractant, ITAC), which act to recruit T cells that express the chemokine receptor CXCR3 (REF. 80).

Many pathogens have evolved to use tissue-specific routes of entry. The persistence of memory $\mathrm{T}$ cells with both antigen and tissue specificity in the peripheral circulation prepares the immune system for possible future interaction with the same pathogen, by providing a population of antigen-specific effector cells pre-targeted to the site where exposure to that pathogen would be most likely to recur.

Although skin-homing T cells are a kind of rapid deployment corps that can be called up to inflamed tissues, there is also evidence for constitutive homing of such $\mathrm{T}$ cells to the skin. T cells recovered from noninflamed skin express high levels of CLA and CCR4 as well as other chemokine receptors ${ }^{81,82}$. Even in the absence of inflammation, leukocytes are observed to tether and roll constitutively on low levels of selectin expressed in dermal post-capillary venules ${ }^{83,84}$. These cells can be thought of as continuously scanning the endothelial-cell surfaces of their target tissue for activation signals and are poised to respond to the slightest hint of danger. Constitutive expression of E-selectin on cutaneous microvessels has been described in both humans and mice, as has expression of CCL17 and ICAM1 (REFS 85-87). Using these sequential interactions, an indeterminate fraction of these $\mathrm{T}$ cells continuously enter the skin and traffic through it, seeking antigen-dependent activation. Antigen-specific T cells can also be detected in the uninflamed skin of patients with atopic dermatitis ${ }^{88}$. It is unclear whether $\mathrm{T}$ cells that home constitutively to the skin are responding to subclinical levels of inflammation or if alternative mechanisms exist that support constitutive expression of endothelial homing components. It is important to note that while they are in the skin, these cells can be thought of as 'resident' $T$ cells; how long they reside in the skin is unknown at present.

Tertiary immune surveillance. Although a given pathogen is most likely to be re-encountered at the same epithelial-cell interface as it was originally engaged, this cannot be guaranteed. Among the T-cell subpopulations produced after an initial antigen encounter are a population of antigen-specific memory cells, known as central memory T cells, that retain expression of CD62 ligand
(CD62L) and CCR7, and the ability to circulate through lymph nodes ${ }^{89}$. These cells can then emigrate from the lymph node in which they were originally produced to lymph nodes throughout the body (including those draining non-cutaneous epithelial-cell interfaces), where they may encounter DCs expressing the same cognate antigen. In this way, the immune system hedges its bets, ensuring a more rapid and effective response even if the next encounter occurs at a different interface.

Although the original description of central memory cells suggested that they could home to lymph nodes only, it has become clear that some T cells can express both central memory and tissue-homing receptors. For example, cells that express CLA, L-selectin, CCR4 and CCR7 are well represented in peripheral blood ${ }^{90}$. One interesting question that awaits investigation is whether central memory T cells that are generated in a skindraining lymph node and resident in a different tissue lymph node (for example, gut or respiratory system lymph node) will, if exposed to antigen, give rise to new effectors of a skin-homing phenotype or effectors that home to the current source tissue, or both.

As seen from this discussion, innate immunesurveillance mechanisms drive the development of adaptive immune responses - that is, injury, inflammation and other danger signals facilitate T-cell development and entry into tissues. Memory T cells and innate immune effector cells can be thought to enter tissues not because they 'see' antigen, but because the local endothelium expresses appropriate counter-receptors and chemoattractants. Only after they have exited the blood can they respond to their antigen that is productively presented. This has important implications for the aetiopathology of inflammatory skin diseases.

Regulatory T cells. Although the mechanisms described earlier highlight the activation and recruitment of effector $\mathrm{T}$ cells, it is clear that REgulatory t CELLS also have an important, though less well characterized, role in dampening exaggerated cutaneous immune responses, as well as in the maintenance of immune tolerance to innocuous self or exogenous antigens ${ }^{91,92}$. Recent reports have indicated that regulatory T-cell subsets might traffic to the skin using pathways that are similar to those used by effector cells ${ }^{73}$. An imbalance in effector/regulatory T-cell recruitment or functions might be a crucial factor in the development of inflammatory skin lesions. Conversely, for those conditions in which the antigen (self or exogenous) can be identified, induction of regulatory $\mathrm{T}$ cells to specific antigens could provide a powerful mechanism for inducing specific tolerance ${ }^{93}$.

\section{Clinical implications}

T-cell-mediated inflammatory skin diseases are extraordinarily common. Also, new therapies for disease have led to new T-cell-mediated skin diseases, notably GVHD after therapeutic allogeneic bone-marrow transplantation. If these diseases are viewed from our current perspective of cutaneous immune surveillance, insights emerge that are useful to understanding their clinical and biological behaviour. 
Table 1 | T cells in inflammatory skin disease

\begin{tabular}{|c|c|c|c|}
\hline Skin disease & T-cell subtype & Antigenic target & Cytokine profile \\
\hline Psoriasis & $\begin{array}{l}\text { Epidermal: } \mathrm{CD}^{+} \\
\text {Dermal: } \mathrm{CD}^{+}\end{array}$ & N.D. (autoantigens?) & $T_{H} 1$ \\
\hline Atopic dermatitis & $\mathrm{CD}^{+}$ & $\begin{array}{l}\text { Extrinsic: allergens } \\
\text { (for example, D. pterynossinus) } \\
\text { Intrinsic: N.D. (autoantigens?) }\end{array}$ & $\begin{array}{l}\text { Acute: } T_{H^{2}}^{2} \\
\text { Chronic: } T_{H} 1\end{array}$ \\
\hline $\begin{array}{l}\text { Allergic contact } \\
\text { dermatitis (contact } \\
\text { hypersensitivity) }\end{array}$ & $\mathrm{CD}^{+}$and $\mathrm{CD} 8^{+}$ & $\begin{array}{l}\text { Haptens (small molecules that } \\
\text { elicit a type IV hypersensitivity } \\
\text { reaction) }\end{array}$ & $T_{H} 1>T_{H}^{2}$ \\
\hline Vitiligo & $\mathrm{CD}^{+}$ & Melanocyte autoantigens & N.D. \\
\hline $\begin{array}{l}\text { Cutaneous T-cell } \\
\text { lymphoma }\end{array}$ & $\mathrm{CD}^{+}$ & Antigen independent & $\mathrm{T}_{H^{2}}$ \\
\hline
\end{tabular}

The evidence described earlier indicates that the cutaneous immune-surveillance system responds to any cutaneous injury that produces danger signals as if it was potentially infectious. Both innate and adaptive immunity are mobilized, and their activities are synergistic. Inappropriate adaptive immunity can be driven by non-specific activation of innate immune pathways, for example, chronic trauma due to scratching of the skin. This in turn can lead to autoinflammatory feedback loops through the recruitment and activation of leukocytes independent of antigen-specific help. Different populations of cells accumulate in specific disease states, reflecting the patterns of expression of vascular adhesion molecules and chemoattractant cytokines induced by the balance of stimuli in that target organ (TABLE 1). This has potential significance for the immunopathology of diseases in organs other than the skin. Our continued understanding of mechanisms of cutaneous immune surveillance will almost certainly provide important insights into immune surveillance and diseases at other environmental epithelial-cell interfaces, including the gut, lungs, oropharyngeal and genital mucosa.

Psoriasis. Psoriasis, which affects $\sim 1-2 \%$ of adults worldwide, is characterized by the formation of erythematous cutaneous plaques covered with scale. Histologically, psoriatic plaques show keratinocyte hyperproliferation and both neutrophil infiltration of the upper epidermis and an infiltrate in the dermis and epidermis replete with T cells, DCs and macrophages.

Psoriasis has an obligate immunological component; therapies directed against T-cell activation and function are highly effective in this disease, and the disease can be initiated in xenograft models by activated $\mathrm{T}$ cells ${ }^{94}$. Increasingly, it is being understood as an autoimmune disease, although the autoantigen(s) has not been identified ${ }^{95}$. The T cells in psoriatic lesions are CLA ${ }^{+}$and produce a type 1 cytokine profile. $\mathrm{CD} 8^{+} \mathrm{T}$ cells in particular have been identified in the epidermis and are thought to have a key role in disease expression.

So far, nearly all successful therapeutic interventions for psoriasis target $\mathrm{T}$ cells. These include corticosteroids, methotrexate, cyclosporine and ultraviolet light (with or without the photosensitizer 8-methoxy psoralens $)^{96}$. More recently, immunobiological therapy has come to the forefront in this disease, with reports of polarizing therapies such as IL-4, IL-10 and IL-11, which inhibit T HELPER 1 (TH1) CELLS and/or enhance TH2-CELL functions, showing promise ${ }^{97-99}$. Other biological agents that inhibit T-cell recruitment or activation, including alefacept (an LFA3immunoglobulin fusion protein), efalizumab (a humanized antibody specific for CD11a) and cytotoxic T lymphocyte antigen 4 (CTLA4)-immunoglobulin fusion protein have shown efficacy in clinical trials; with alefacept and efalizumab recently winning FDA approval ${ }^{100}$. Biological agents that inhibit TNF are also quite effective - etanercept is a p75 TNF receptor-IgG Fc fusion protein and infliximab is a humanized monoclonal antibody specific for TNF. Both of these compounds have been shown to be effective in the treatment of psoriasis ${ }^{101}$. Interestingly, short-term treatment with an antibody specific for E-selectin was recently shown to be ineffective in psoriasis, indicating that once lesions are established, blocking T-cell rolling on E-selectin is insufficient to block disease activity ${ }^{102}$. By contrast, Efomycin $\mathrm{M}$ - a small molecule inhibitor of selectin binding - has recently been shown to be effective in animal models of psoriasis and might indicate a further role for inhibition of selectins in the treatment of human psoriasis ${ }^{103}$.

The interplay of innate and adaptive immune responses in psoriasis is seen in the Koebner phenomenon, in which physical trauma provokes the development of a psoriatic lesion. As discussed earlier, skin trauma leads to the release of innate immune activators, such as IL-1 and TNF, and results in the upregulation of E-selectin and ICAM1 expression on local dermal post-capillary venules. This leads to the activation of resident $\mathrm{T}$ cells and the recruitment of CLA ${ }^{+}$ $\mathrm{T}$ cells from the blood, including the presumed subpopulation that is specific for psoriatic autoantigens. Innate immune activators also induce the maturation of DCs in the dermis and epidermis, enhancing their activity as APCs, and encouraging the activation and proliferation of the recruited $\mathrm{T}$ cells and the development of a psoriatic plaque. 
Atopic dermatitis. Atopic dermatitis is a common disease that affects people of all age groups worldwide ${ }^{104,105}$. The prevalence has been reported to vary between $7 \%$ and $17 \%$ for children, and in $60 \%$ or more of these individuals the disease can persist into adulthood ${ }^{104,106-109}$.

Atopy is the hereditary predisposition to allergy or hypersensitivity, with the term atopic dermatitis used to describe a group of skin diseases associated with atopic conditions (allergic rhinitis, allergic keratoconjunctivitis, asthma and eczema) that might be seen in all age groups. Clinically, atopic dermatitis is characterized by the development of erythematous, exudative lesions in skin folds that are associated with intense itching. Histopathological sections show perivascular infiltration of the dermis and epidermis by lymphocytes, monocytes and macrophages.

Acute atopic dermatitis is mediated by $\mathrm{T}$ cells specific for environmental antigens, although there are subgroups of atopic dermatitis that might have different mechanisms of triggering and maintaining inflammation (for example, extrinsic/allergic atopic dermatitis versus intrinsic/non-allergic atopic dermatitis) $)^{6,110,111}$. The house-dust mite Dermatophagoides pterynossinus is a common source of extrinsic antigen, and T cells specific for this antigen can be identified in lesional and non-lesional skin of selected individuals ${ }^{112}$. Antigen presentation is enhanced by the presence of highaffinity IgE receptors on Langerhans cells, which internalize antibody-antigen complexes, process antigen and present it to T cells within evolving lesions. Interestingly, as atopic dermatitis lesions become more chronic, the cytokine profile they exhibit shifts from $\mathrm{T}_{\mathrm{H}} 2$ to $\mathrm{T}_{\mathrm{H}} 1$ type ${ }^{113}$. The mechanism behind this switch is incompletely understood.

The interplay between innate and acquired immunity emerges in this disease also. It is well established that scratching of pruritic non-lesional skin can lead to the emergence of new lesions. Presumably this occurs by the trauma of scratching, as in the Koebner response described earlier. A second link comes at the level of bacterial colonization and superinfection. Staphylococcus aureus is readily cultured from atopic skin, particularly lesional skin, and it might be that stimulation by bacterial superantigens or the activation of TLRs on resident skin cells leads to chronic release of primary cytokines. Recent studies have shown that atopic epidermis, unlike psoriatic epidermis, does not produce the antibacterial peptides $\beta$-defensin and cathelicidin in response to such infection ${ }^{114}$, and that IL- 4 blocks the induction of these antimicrobial peptides from keratinocytes ${ }^{115}$. So, a product of $\mathrm{T}_{\mathrm{H}} 2$ cells blocks one pathway of innate immune activation, leading to bacterial overgrowth and the induction of another innate immune pathway. This, in turn, facilitates the continued activation of the adaptive immune system, including the recruitment and activation of atopic $\mathrm{T}_{\mathrm{H}} 2$ cells, and perpetuation of the lesion.

Allergic contact dermatitis. Allergic contact dermatitis (ACD), also referred to as contact hypersensitivity, is a T-cell-mediated type IV DELAYED-TYPE HYPERSENSITIVITY reaction to specific environmental antigens and is manifested by varying degrees of erythema, spongiosis (epidermal oedema) and vesiculation. Most contact allergens are themselves irritants (for example, uroshiol or poison ivy), and they therefore provide both antigen and danger signals when they contact skin. The pathophysiology of this disorder is multifactorial, but is characterized by the infiltration and activation of both $\mathrm{CD}^{+}$and $\mathrm{CD}^{+} \mathrm{T}$ cells ${ }^{91,116}$. A general model in which allergen-specific type $1 \mathrm{CD} 4^{+}$and $\mathrm{CD} 8^{+} \mathrm{T}$ cells act as effectors and type $2 \mathrm{CD} 4^{+} \mathrm{T}$ cells act as regulatory elements is supported by investigations in animal models ${ }^{117}$. Accumulation of eosinophils and enhanced production of IgE can also be seen ${ }^{118}$. ACD requires a sensitization phase of 1-2 weeks after exposure, in which small molecule components of the active agent bind to endogenous proteins and act as haptens to induce the activation and proliferation of antigen-specific T cells, which then mature into skin-homing effector memory cells. Subsequent epicutaneous exposures result in symptoms that progress over hours to days and reflect activation of resident antigen-specific effector T cells as well as their further local accumulation from the blood. This is followed by accumulation of $\mathrm{CD} 4^{+} \mathrm{T}$ cells that produce $\mathrm{T}_{\mathrm{H}}$ 2-type cytokines (for example, IL-5 and IL-13) in chronic and resolving lesions. Recent studies have implicated IL-10, produced by $\mathrm{CD} 4{ }^{+} \mathrm{CD} 25^{+}$regulatory $\mathrm{T}$ cells, as a key factor in the down-modulation of allergic responses in the skin ${ }^{92,119}$.

Cutaneous graft-versus-host disease. Acute cutaneous GVHD describes a distinctive syndrome of dermatitis, developing within 100 days of allogeneic haematopoieticcell transplantation ${ }^{120}$. Chronic cutaneous GVHD describes a more indolent syndrome that develops after day 100. Development of GVHD depends on the transfer of immunologically competent cells, such as mature $\mathrm{T}$ cells included in bone-marrow transplants or resident in solid organ transplants, the presence of alloantigens on host tissues that can stimulate the graft cells and the lack of an effective host immunological response to the graft. Acute cutaneous GVHD is characterized initially by a rash or by a generalized redness of the skin and desquamation. Chronic cutaneous GVHD can lead to areas of thickened skin or sclerodermatous changes that sometimes cause contractures and limitation of joint mobility. The predilection of GVHD for the skin and the gastrointestinal tract has led to speculation that it is mediated in these respective tissues by antigen-specific $\mathrm{T}$ cells with distinct skin- or gut-homing properties ${ }^{1,64}$. This hypothesis has not been formally tested.

Cutaneous T-cell lymphoma. We and others have proposed that CTCLs are malignancies of skin-homing T cells ${ }^{1,121}$. The most common form of this uncommon disease - mycosis fungoides - is characterized by patches and plaques on the skin, often in nonsun-exposed areas, which can resemble eczematous dermatitis. Histopathological features of CTCL include the clustering of malignant $\mathrm{T}$ cells in the epidermis, often around Langerhans cells. There is evidence that 
expression of homing molecules determines the anatomic localization of these cells ${ }^{81}$. Tumour cells that are CLA and CCR4 positive but lack expression of either L-selectin or CCR7 can be found in the skin, whereas cells that express both L-selectin and CCR7 are associated with lymph-node involvement. The CTCL cells almost invariably produce $\mathrm{T}_{\mathrm{H}}$ 2-type cytokines $^{122}$. Recently, evidence has emerged that CTCL is associated with marked disruption of the T-cell repertoire, indicating that it might be a systemic disease rather than simply a clonal malignancy of skin-homing $\mathrm{T}$ cells ${ }^{123}$.

Vitiligo. Vitiligo is characterized by complete or partial depigmentation of the epidermis. It is an acquired progressive disorder in which some or all of the melanocytes that reside in the interfollicular epidermis and, occasionally, in the hair follicles are selectively destroyed ${ }^{124}$. Vitiligo is relatively frequent, occurring in $1-2 \%$ of the population. $\mathrm{CD}^{+} \mathrm{T}$ cells specific for antigens that are uniquely expressed by melanocytes are frequently seen in these patients, leading to the suggestion

\section{Box 1 | Vaccinating against smallpox in atopic patients}

Smallpox (variola major) typically enters the host through the oropharynx, invades the mucosal epithelium, and migrates to regional lymph nodes, and then to the spleen, the bone marrow and other lymph nodes, where viral replication occurs ${ }^{151}$. After an incubation period of 12-14 days, virus enters the blood within leukocytes, which seed the skin and produce the characteristic skin lesions (pox), whereas most other tissues are spared. The fact that virus seems to travel in leukocytes that specifically exit blood vessels in the papillary dermis indicates that variola virus preferentially associates with leukocytes that can home to skin; alternatively, it might be that only skin tissues can support the subsequent replication steps that are required for lesion formation.

Protective vaccination with vaccinia virus depends on delivery of the virus to the epidermis by a technique known as scarification, leading to an epidermal 'pox' reaction - a cutaneous T-cell-mediated delayed-type hypersensitivity reaction presumably involving vaccinia-virus-specific skin-homing $\mathrm{T}$ cells. Both subcutaneous and intramuscular vaccinations fail to provoke a pox reaction and do not effectively incite neutralizing antibodies or vaccinia-virus-specific cytotoxic T cells ${ }^{152}$.

Patients with either active or quiescent atopic dermatitis are at risk after immunization for the development of eczema vaccinatum, which results from an inability of the host to control the spread of virus from the inoculation site, and is associated with substantial morbidity and mortality ${ }^{107,153}$. We hypothesize that atopic individuals have defects in both innate and acquired immune responses to vaccinia virus. Atopic patients preferentially generate $T$ helper $2\left(\mathrm{~T}_{\mathrm{H}} 2\right)$-cell responses to antigens encountered through the skin, and increased levels of the $\mathrm{T}_{\mathrm{H}}$ 2-type cytokine interleukin-4 (IL-4) can be detected in both affected and unaffected skin $^{154}$. Ectromelia (mousepox) virus genetically engineered to produce IL-4 results in a lethal disease in mice that are normally resistant to unmodified ectromelia, indicating a role for this cytokine in restricting immune responses to pox viruses ${ }^{155}$. Production of $\mathrm{T}_{\mathrm{H}}$ 1-type cytokines, such as interferon- $\gamma$, and cytotoxic $\mathrm{T}$-cell functions are also impaired in patients with atopic dermatitis ${ }^{91,156}$. T-cell homing might be dysfunctional in these patients as well. In mice, the generation of $\mathrm{T}_{\mathrm{H}}$ 1-type, but not $\mathrm{T}_{\mathrm{H}}$ 2-type, cytokines, is associated with a skin-homing phenotype ${ }^{157}$. The presence of skin-homing $\mathrm{T}_{\mathrm{H}} 2$ cells in atopic patients might represent an uncoupling of this association ${ }^{158}$. Surprisingly, even innate immunity might be impaired in these patients ${ }^{114}$. The production of IL-18 is increased in atopic dermatitis ${ }^{159}$, and keratinocytes from patients with atopic dermatitis produce a different array of cytokines and chemokines than do keratinocytes from non-atopic individuals ${ }^{160-162}$. that vitiligo is a T-cell-mediated autoimmune disorder ${ }^{125}$. Interestingly, vitiligo is most prominent in areas that are subject to minor trauma, providing another diseaserelated link between innate and acquired immunity in inflammatory skin diseases.

Other inflammatory skin disorders might also be mediated or modulated by these mechanisms. Although there are few data present in the literature, further investigations might identify a role for dysregulation of leukocyte homing in the pathogenesis of these and other skin conditions. It is not possible to discuss the full range of implications in this review.

\section{Vaccine development}

The concepts of immune surveillance and tissue-specific homing have important implications for the rational design of vaccines, as highlighted by the example of smallpox (BOX 1). Not only must the antigen be administered in a manner that leads to DC maturation and migration to lymph nodes (danger signals or adjuvant effects), but also the route of administration might have marked qualitative and quantitative effects on the desired protective immune response. Such considerations are taking on a broader scope and purpose, with interest in the development of vaccines against tumours, HIV and emerging infectious agents responsible for diseases such as Lyme disease, West Nile virus disease and severe acute respiratory syndrome (SARS). Even longstanding immunization protocols, such as those established more than 40 years ago for smallpox, are under active investigation for improvements that might reduce complications while maintaining effectiveness. The findings outlined earlier indicate that vaccination through the skin (intradermal) will be most efficient at stimulating skin-homing effector cells, whereas alternative routes (for example, oral and intramuscular) will most efficiently generate effector memory $\mathrm{T}$ cells that are directed towards other sites.

Although aggressive stimulation with adjuvants might bypass the anatomically specific elements of the immune response by driving broad production of central memory cells, it might be preferable in some cases to limit responses to a desired site to avoid potential complications in other tissues.

Tumour vaccines. Our knowledge of leukocyte homing and immune-surveillance mechanisms also has implications for the field of antitumour vaccines. Despite considerable work in this area, the clinical success of antitumor vaccinations has been limited so far. One reason for this could be that the methods chosen for immunization are insufficient or inappropriate for the tumour of interest. Malignant melanoma is a cancer of melanocytes, or pigment cells, that reside in the epidermis and hair follicles and produce melanin. There is convincing evidence that malignant melanoma can evoke humoral and cellular immune responses in some patients. The radial growth phase of primary melanoma, associated with slow and superficial growth without prominent dermal invasion, is regularly associated with a marked dermal lymphocytic 
reaction, sometimes resulting in partial tumour destruction ${ }^{126-128}$. Clonal expansion of T cells occurs in regressing primary melanoma, and lymphocytes explanted from such lesions are cytotoxic in vitro to autologous melanoma cells ${ }^{129-132}$. Although a rapid lymphocytic infiltrate in the vertical growth phase (where rapid growth and prominent dermal invasion occur) of primary melanoma occurs less frequently, this response is correlated with prolonged survival and a reduced incidence of metastatic disease ${ }^{133-135}$.

Many strategies to enhance antimelanoma immunity are under investigation at present, based on whole tumour cells or defined tumour antigens ${ }^{136-144}$. In the development of such protocols, relatively little attention has been paid to the route of vaccination used $^{145-147}$. We would predict that immunization through the skin would generate a skin-homing effector T-cell response, but might not be expected to target metastatic tumours in the lungs or gastrointestinal tract efficiently. Under normal circumstances, antimelanoma T-cell responses might first be expected to develop in the local skin-draining lymph nodes and should lead to the generation of skin-homing memory effector cells. Indeed, IL-2 therapy (which expands and activates pre-existing memory effector cell populations) and DC vaccine therapies result in more rapid responses to the cutaneous metastases of melanoma than to metastases elsewhere ${ }^{148}$. For immunization with melanoma-antigen-pulsed DCs, if they are injected into the skin, they could traffic through afferent lymphatics to draining lymph nodes, generating skin-homing memory effector cells. Injected intravenously, however, their migration patterns remain largely unknown.
Protocols to enhance DC migration to peripheral lymph nodes are under investigation ${ }^{149}$. It is also important to consider the effects of vaccination strategies on DC activation, as antigen presentation by immature DCs has been shown to stimulate antigen-specific inhibition of effector T-cell functions ${ }^{93,150}$.

\section{Conclusions}

Investigation of leukocyte trafficking to the skin has provided insight into the role of primary, secondary and tertiary immune surveillance in normal cutaneous immune function and in the development of inflammatory skin diseases. The few disorders that we have discussed in detail are only a subset of clinically important T-cell-mediated skin diseases, which also include drug eruptions, alopecia areata, lichen planus and many others. The number and diversity of these diseases are testament to how many things can potentially go wrong in a complex system such as cutaneous immune surveillance. At the same time, it is extraordinary that the cutaneous immune system works as well as it does most of the time. The concept that exaggerated or inappropriate activity of an important immune-surveillance mechanism can cause organ-specific diseases might extend to inflammatory bowel disease and asthma, which occur at two other epithelial-cell interfaces with the environment. The challenge will be to design therapies that target the elements of cutaneous immune surveillance that are overactive in specific diseases of the skin or other organs, while leaving intact those functions that are central to survival in a hostile world filled with opportunistic pathogens.
1. Robert, C. \& Kupper, T. S. Inflammatory skin diseases, T cells, and immune surveillance. N. Engl. J. Med. 341 1817-1828 (1999).

2. Uthayakumar, S., Nandwani, R., Drinkwater, T., Nayagam, A. T. \& Darley, C. R. The prevalence of skin disease in HIV infection and its relationship to the degree of immunosuppression. Br. J. Dermatol. 137, 595-598 (1997).

3. Lugo-Janer, G., Sánchez, J. L. \& Santiago-Delpin, E. Prevalence and clinical spectrum of skin diseases in kidney transplant recipients. J. Am. Acad. Dermatol. 24, 410-414 (1991).

4. Kadunce, D. P. \& Krueger, G. G. Pathogenesis of psoriasis Dermatol. Clin. 13, 723-737 (1995).

5. Leung, D. Y. Atopic dermatitis: immunobiology and treatment with immune modulators. Clin. Exp. Immunol. 107 Suppl. 1, 25-30 (1997).

6. Galli, E. et al. Atopic dermatitis: molecular mechanisms, clinical aspects and new therapeutical approaches. Curr. Mol. Med. 3, 127-138 (2003).

7. González, F. J. et al. Participation of T lymphocytes in cutaneous allergic reactions to drugs. Clin. Exp. Allergy 28 Suppl. 4, 3-6 (1998).

8. Porter, S. R., Kirby, A., Olsen, I. \& Barrett, W. Immunologic aspects of dermal and oral lichen planus: a review. Oral Surg. Oral Med. Oral Pathol. Oral Radiol. Endod. $\mathbf{8 3}$ 358-366 (1997).

9. McDonagh, A. J. \& Messenger, A. G. The pathogenesis of alopecia areata. Dermatol. Clin. 14, 661-670 (1996).

10. Boh, E. E. \& Millikan, L. E. Vesiculobullous diseases with prominent immunologic features. JAMA 268, 2893-2898 (1992).

11. Wong, E., Camp, R. D. R. \& Greaves, M. W. The responses of normal and psoriatic skin to single and multiple topical applications of leukotriene B4. J. Invest. Dermatol. 84, 421-423 (1985).

12. Krueger, J. G., Wolfe, J. T. \& Nabeya, R. T. Successful ultraviolet $\mathrm{B}$ treatment of psoriasis is accompanied by a reversal of keratinocyte pathology and by selective depletion of intraepidermal T cells. J. Exp. Med. 182 2057-2068 (1995).

13. Gottlieb, S. L., Gilleaudeau, P. \& Johnson, R. Response of psoriasis to be lymphocyte-selective toxin (DAB389IL-2) suggests a primary immune, but not keratinocyte, pathogenic basis. Nature Med. 1, 442-447 (1995).

14. Lim, K. K. et al. Cyclosporine in the treatment of dermatologic disease: an update. Mayo Clin. Proc. 71, 1182-1191 (1996).

15. Kupper, T. S. \& Groves, R. W. The interleukin-1 axis and cutaneous inflammation. J. Invest. Dermatol. 105, 62S-66S (1995).

16. Murphy, J. E., Robert, C. \& Kupper, T. S. Interleukin-1 and cutaneous inflammation: a crucial link between innate and acquired immunity. J. Invest. Dermatol. 114, 602-608 (2000).

17. Heufler, C. et al. Interleukin 7 is produced by murine and human keratinocytes. J. Exp. Med. 178, 1109-1114 (1993).

18. Yang, D., Chertov, O. \& Oppenheim, J. J. The role of mammalian antimicrobial peptides and proteins in awakening of innate host defences and adaptive immunity. Cell. Mol. Life Sci. 58, 978-989 (2001).

19. Gallo, R. L., Murakami, M., Ohtake, T. \& Zaiou, M. Biology and clinical relevance of naturally occurring antimicrobial peptides. J. Allergy Clin. Immunol. 110, 823-831 (2002).

20. Kupper, T. S., Chua, A. O., Flood, P., McGuire, J. \& Gubler, U. Interleukin 1 gene expression in cultured human keratinocytes is augmented by ultraviolet irradiation. J. Clin. Invest. 80, 430-436 (1987).

21. Wood, L. C., Elias, P. M. \& Calhoun, C. Barrier disruption stimulates interleukin- $1 \alpha$ expression and release from a preformed pool in murine epidermis. J. Invest. Dermatol. 106, 397-403 (1996).

22. Luger, T. A., Scholzen, T. \& Grabbe, S. The role of $\alpha$-melanocyte-stimulating hormone in cutaneous biology. J. Investig. Dermatol. Symp. Proc. 2, 87-93 (1997).
23. Dinarello, C. A. Interleukin-1, interleukin-1 receptors and interleukin-1 receptor antagonist. Int. Rev. Immunol. 16, 457-499 (1998).

24. Fuhlbrigge, R. C. \& Kupper, T. S. In Allergic Skin Disease (eds Leung, D. Y. M. \& Greaves, M. W.) 29-52 (Marcel Dekker, New York, 2000).

25. Takashima, A. \& Bergstresser, P. R. Cytokine-mediated communication by keratinocytes and Langerhans cells with dendritic epidermal T cells. Semin. Immunol. 8, 333-339 (1996).

26. Dahl, M. Clinical Immunodermatology (Mosby, St. Louis, 1996).

27. Stoll, S. et al. Production of IL-18 (IFN- $\gamma$-inducing factor) messenger RNA and functional protein by murine keratinocytes. J. Immunol. 159, 298-302 (1997).

28. Steinhoff, M., Brzoska, T. \& Luger, T. A. Keratinocytes in epidermal immune responses. Curr. Opin. Allergy Clin. Immunol. 1, 469-476 (2001).

29. Kumar, S. et al. Identification and initial characterization of four novel members of the interleukin-1 family. J. Biol. Chem. 275, 10308-10314 (2000).

30. Takeda, K., Kaisho, T. \& Akira, S. Toll-like receptors. Annu. Rev. Immunol. 21, 335-376 (2003).

31. Sieling, P. A. \& Modlin, R. L. Toll-like receptors: mammalian 'taste receptors' for a smorgasbord of microbial invaders. Curr. Opin. Microbiol. 5, 70-75 (2002).

32. Medzhitov, R. Toll-like receptors and innate immunity. Nature Rev. Immunol. 1, 135-145 (2001).

33. Barton, G. M. \& Medzhitov, R. Control of adaptive immune responses by Toll-like receptors. Curr. Opin. Immunol. 14, 380-383 (2002).

34. Yang, R. B. et al. Toll-like receptor-2 mediates lipopolysaccharide-induced cellular signalling. Nature $\mathbf{3 9 5}$ 284-288 (1998).

This paper identified Toll-like receptor 2 (TLR2) as the receptor for lipopolysaccharide on mammalian cells, leading to an explosion of interest in TLRs as 
innate immune-response elements, as highlighted in references $35-40$.

35. Brightbill, H. D. et al. Host defense mechanisms triggered by microbial lipoproteins through toll-like receptors. Science $\mathbf{2 8 5}$ 732-736 (1999).

36. Aliprantis, A. O. et al. Cell activation and apoptosis by bacterial lipoproteins through toll-like receptor-2. Science $\mathbf{2 8 5}$, 736-739 (1999).

37. Hayashi, F. et al. The innate immune response to bacterial flagellin is mediated by Toll-like receptor 5 . Nature $\mathbf{4 1 0}$ 1099-1103 (2001).

38. Tada, H. et al. Saccharomyces cerevisiae- and Candida albicans-derived mannan induced production of tumo necrosis factor $\alpha$ by human monocytes in a CD14- and Tolllike receptor 4-dependent manner. Microbiol. Immunol. 46 503-512 (2002).

39. Hemmi, H. et al. A Toll-like receptor recognizes bacterial DNA. Nature 408, 740-745 (2000)

40. Wagner, $\mathrm{H}$. Interactions between bacterial CpG-DNA and TLR9 bridge innate and adaptive immunity. Curr. Opin. Microbiol. 5, 62-69 (2002).

41. Jarrossay, D., Napolitani, G., Colonna, M., Sallusto, F. \& Lanzavecchia, A. Specialization and complementarity in microbial molecule recognition by human myeloid and plasmacytoid dendritic cells. Eur. J. Immunol. 31 3388-3393 (2001)

42. Kadowaki, N. et al. Subsets of human dendritic cell precursors express different toll-like receptors and respond to different microbial antigens. J. Exp. Med. 194, 863-869 (2001).

43. Krug, A. et al. Toll-like receptor expression reveals CpG DNA as a unique microbial stimulus for plasmacytoid dendritic cells which synergizes with CD40 ligand to induce high amounts of IL-12. Eur. J. Immunol. 31, 3026-3037 (2001).

44. Medzhitov, R. \& Janeway, C. A. Innate immunity: the virtues of a nonclonal system of recognition. Cell 91, 295-298 (1997).

45. Barnes, P. J. Nuclear factor-кB. Int. J. Biochem. Cell Biol. 29 867-870 (1997)

46. von Andrian, U. H. \& Mackay, C. R. T-cell function and migration. Two sides of the same coin. N. Engl. J. Med. 343, 1020-1034 (2000)

47. Supajatura, V. et al. Differential responses of mast cell Toll-like receptors 2 and 4 in allergy and innate immunity. J. Clin. Invest. 109, 1351-1359 (2002).

48. Marshall, J. S., McCurdy, J. D. \& Olynych, T. Toll-like receptor-mediated activation of mast cells: implication for allergic disease? Int. Arch. Allergy Immunol. 132, 87-97 (2003)

49. McCurdy, J. D., Olynych, T. J., Maher, L. H. \& Marshall, J. S. Cutting edge: distinct Toll-like receptor 2 activators selectively induce different classes of mediator production from human mast cells. J. Immunol. 170, 1625-1629 (2003)

50. Inaba, K. et al. Generation of large numbers of dendritic cells from mouse bone marrow cultures supplemented with granulocyte/macrophage colony-stimulating factor. J. Exp. Med. 176, 1693-1702 (1992)

51. Lenz, A., Heine, M., Schuler, G. \& Romani, N. Human and murine dermis contain dendritic cells. J. Clin. Invest. $\mathbf{9 2}$ 2587-2596 (1993)

52. Banchereau, J. \& Steinman, R. M. Dendritic cells and the control of immunity. Nature 392, 245-252 (1998). This review brings together the view of dendritic cells (DCs) as the central mediators between innate and adaptive immune responses.

53. Hart, D. N. J. Dendritic cells: unique leukocyte populations which control the primary immune response. Blood $\mathbf{9 0}$ 3245-3287 (1997)

54. Pierre, P. et al. Developmental regulation of $\mathrm{MHC}$ class II transport in mouse dendritic cells. Nature $\mathbf{3 8 8}, 787-792$ (1997).

55. Schuller, E. et al. In situ expression of the co-stimulatory molecules CD80 and CD86 on langerhans cells and inflammatory dendritic epidermal cells (IDEC) in atopic dermatitis. Arch. Dermatol. Res. 293, 448-454 (2001)

56. Wollenberg, A., Kraft, S., Hanau, D. \& Bieber, T. Immunomorphological and ultrastructural characterization of Langerhans cells and a novel, inflammatory dendritic epidermal cell (IDEC) population in lesional skin of atopic eczema. J. Invest. Dermatol. 106, 446-453 (1996).

57. Picker, L. J., Michie, S. A., Rott, L. S. \& Butcher, E. C. A unique phenotype of skin-associated lymphocytes in human. Preferential expression of the HECA-452 epitope by benign and malignant $T$ cells at cutaneous sites. Am. J. Pathol. 136, 1053-1068 (1990).

\section{This report provided the first evidence of a specific} homing receptor for non-lymphoid tissues.

58. Pitzalis, C. et al. Cutaneous lymphocyte antigen-positive T lymphocytes preferentially migrate to the skin but not to the joint in psoriatic arthritis. Arthritis Rheum. 39 137-145 (1996).
This study, together with references 62 and 64, firmly established cutaneous lymphocyte antigen (CLA) as a specific marker of skin-homing $T$ cells.

59. Sigmundsdottir, H., Gudjonsson, J. E., Jonsdottir, I., Ludviksson, B. R. \& Valdimarsson, H. The frequency of $\mathrm{CLA}^{+} \mathrm{CD} 8^{+} \mathrm{T}$ cells in the blood of psoriasis patients correlates closely with the severity of their disease. Clin. Exp. Immunol. 126, 365-369 (2001).

60. Noorduyn, L. et al. Differential expression of the HECA-452 antigen (cutaneous lymphocyte associated antigen, CLA) in cutaneous and non-cutaneous T-cell lymphomas. Histopathology 21, 59-64 (1992).

61. Santamaria Babi, L. F., Perez Soler, M. T., Hauser, C. \& Blaser, K. Skin-homing T cells in human cutaneous allergic inflammation. Immunol. Res. 14, 317-324 (1995).

62. Santamaria Babi, L. F. et al. Circulating allergen-reactive T cells from patients with atopic dermatitis and allergic contact dermatitis express the skin-selective homing receptor, the cutaneous lymphocyte-associated antigen. J. Exp. Med. 181, 1935-1940 (1995).

63. Tanaka, Y. et al. Distinct phenotype of leukemic T cells with various tissue tropisms. J. Immunol. 158, 3822-3829 (1997)

64. Davis, R. E. \& Smoller, B. R. T lymphocytes expressing HECA-452 epitope are present in cutaneous acute graftversus-host disease and enthema multiforme, but not in acute graft-versus-host disease in gut organs. Am. J. Pathol. 141, 691-698 (1992).

65. Rook, A. H. \& Heald, P. The immunopathogenesis of cutaneous T-cell lymphoma. Hematol. Oncol. Clin. North Am. 9, 997-1010 (1995).

66. Berlin, C. et al. $\alpha_{4} \beta_{7}$ integrin mediates lymphocyte binding to the mucosal vascular addressin MAdCAM-1. Cell 74 185-195 (1993).

This study identified integrin $\alpha_{4} \beta_{7}$ as the T-cell-homing receptor for Peyer's patches.

67. Mora, J. R. et al. Selective imprinting of gut-homing T cells by Peyer's patch dendritic cells. Nature 424, 88-93 (2003).

68. Dudda, J. C. Simon, J. C. \& Martin, S. Dendritic cell immunization route determines $\mathrm{CD} 8^{+} T$ cell trafficking to inflamed skin: role for tissue microenvironment and dendritic cells in establishment of T cell-homing subsets. J. Immunol. 172, 857-863 (2004).

References 67 and 68 showed that $T$ cells responding to DCs from different anatomic sites are induced to express different patterns of homing receptors.

69. Koelle, D. M. et al. Expression of cutaneous lymphocyteassociated antigen by $\mathrm{CD} 8^{+} \mathrm{T}$ cells specific for a skin-tropic virus. J. Clin. Invest. 110, 537-548 (2002).

70. Rott, L. S. et al. Expression of mucosal homing receptor $\alpha_{4} \beta_{7}$ by circulating CD4+ cells with memory for intestinal rotavirus. J. Clin. Invest. 100, 1204-1208 (1997).

References 69 and 70 provided evidence for tissuespecific homing of $\mathrm{CD}^{+}$cytotoxic T cells to the skin and to the gut in response to infection with tissuetropic viruses.

71. Armerding, D. \& Kupper, T. S. Functional cutaneous lymphocyte antigen can be induced in essentially al peripheral blood T lymphocytes. Int. Arch. Allergy Immunol. 119, 212-222 (1999).

72. Akdis, M., Klunker, S., Schliz, M., Blaser, K. \& Akdis, C. A. Expression of cutaneous lymphocyte-associated antigen on human $\mathrm{CD}^{+}$and $\mathrm{CD}^{+}{ }^{+} \mathrm{T}_{2}$ cells. Eur. J. Immunol. $\mathbf{3 0}$ 3533-3541 (2000)

73. Colantonio, L., lellem, A., Sinigaglia, F. \& D'Ambrosio, D. Skin-homing $\mathrm{CLA}^{+} \mathrm{T}$ cells and regulatory $\mathrm{CD} 25^{+} \mathrm{T}$ cells represent major subsets of human peripheral blood memory T cells migrating in response to CCL1/I-309. Eur. J. Immunol. 32, 3506-3514 (2002).

74. Biedermann, T. et al. Targeting CLAVE-selectin interactions prevents CCR4-mediated recruitment of human $\mathrm{T}_{H} 2$ memory cells to human skin in vivo. Eur. J. Immunol. 32 3171-3180 (2002).

75. Hudak, S. et al. Immune surveillance and effector functions of CCR10+ skin homing T cells. J. Immunol. 169, 1189-1196 (2002)

76. Reiss, Y., Proudfoot, A. E., Power, C. A. Campbell, J. J. \& Butcher, E. C. CC chemokine receptor (CCR) 4 and the CCR10 ligand cutaneous T cell-attracting chemokine (CTACK) in lymphocyte trafficking to inflamed skin. J. Exp. Med. 194, 1541-1547 (2001).

77. Morales, J. et al. CTACK, a skin-associated chemokine that preferentially attracts skin-homing memory T cells Proc. Natl Acad. Sci. USA 96, 14470-14475 (1999).

78. Homey, B. et al. CCL27-CCR10 interactions regulate T cellmediated skin inflammation. Nature Med. 8, 157-165 (2002).

79. Fitzhugh, D. J., Naik, S., Caughman, S. W. \& Hwang, S. T. Cutting edge: $\mathrm{C}-\mathrm{C}$ chemokine receptor 6 is essential for arrest of a subset of memory $T$ cells on activated derma microvascular endothelial cells under physiologic flow conditions in vitro. J. Immunol. 165, 6677-6681 (2000).
80. Klunker, S. et al. A second step of chemotaxis after transendothelial migration: keratinocytes undergoing apoptosis release IFN- $\gamma$-inducible protein 10, monokine induced by IFN- $\gamma$, and IFN- $\gamma$-inducible $\alpha$-chemoattractant for $\mathrm{T}$ cell chemotaxis toward epidermis in atopic dermatitis. J. Immunol. 171, 1078-1084 (2003).

81. Ferenczi, K., Fuhlbrigge, R. C., Pinkus, J., Pinkus, G. S. \& Kupper, T. S. Increased CCR4 expression in cutaneous T cell lymphoma. J. Invest. Dermatol. 119, 1405-1410 (2002).

82. Kunkel, E. J. et al. Expression of the chemokine receptors CCR4, CCR5, and CXCR3 by human tissue-infiltrating lymphocytes. Am. J. Pathol. 160, 347-355 (2002).

83. Janssen, G. H., Tangelder, G. J., Oude Egbrink, M. G. \& Reneman, R. S. Spontaneous leukocyte rolling in venules in untraumatized skin of conscious and anesthetized animals. Am. J. Physiol. 267, H1199-H1204 (1994).

84. Robert, C. et al. Interaction of dendritic cells with skin endothelium: a new perspective on immunosurveillance. J. Exp. Med. 189, 627-636 (1999)

85. Chong, B. F., Murphy, J.-E., Kupper, T. S. \& Fuhlbrigge, R. C. E-selectin, thymus- and activation-regulated chemokine/CCL17, and intercellular adhesion moleculeare constitutively coexpressed in dermal microvessels: a foundation for a cutaneous immunosurveillance system. J. Immunol. 172, 1575-1581 (2004).

86. Weninger, W. et al. Specialized contributions by $\alpha(1,3)$ fucosyltransferase-IV and FucT-VII during leukocyte rolling in dermal microvessels. Immunity 12, 665-676 (2000).

87. Groves, R. W. et al. Effect of in vivo interleukin-1 on adhesion molecule expression in normal human skin. J. Invest. Dermatol. 98, 384-387 (1992).

88. Langeveld-Wildschut, E. G. et al. Clinical and immunologic variables in skin of patients with atopic eczema and either positive or negative atopy patch test reactions. J. Allergy Clin. Immunol. 105, 1008-1016 (2000).

89. Sallusto, F., Lenig, D., Forster, R., Lipp, M. \& Lanzavecchia, A Two subsets of memory T lymphocytes with distinct homing potentials and effector functions. Nature 401, 708-712 (1999).

This study distinguished effector memory $\mathrm{T}$ cells, which participate in peripheral inflammatory responses, from central memory $\mathrm{T}$ cells, which migrate through secondary lymphoid tissues and provide long-term memory.

90. Campbell, J. J. et al. CCR7 expression and memory T cell diversity in humans. J. Immunol. 166, 877-884 (2001).

91. Girolomoni, G., Sebastiani, S., Albanesi, C. \& Cavani, A. T-cell subpopulations in the development of atopic and contact allergy. Curr. Opin. Immunol. 13, 733-737 (2001).

92. Cavani, A. et al. Human $\mathrm{CD}_{2} 5^{+}$regulatory T cells maintain immune tolerance to nickel in healthy, nonallergic individuals. J. Immunol. 171, 5760-5768 (2003).

93. Mahnke, K., Qian, Y., Knop, J. \& Enk, A. H. Induction of $\mathrm{CD} 4^{+} / \mathrm{CD} 25^{+}$regulatory $\mathrm{T}$ cells by targeting of antigens to immature dendritic cells. Blood 101, 4862-4869 (2003).

94. Wrone-Smith, T. \& Nickoloff, B. J. Dermal injection of immunocytes induces psoriasis. J. Clin. Invest. 98, 1878-1887 (1996).

This study firmly established that psoriasis is dependent on immune cells using an animal model of human skin grafted onto immune-deficient mice and injected with autologous $\mathrm{T}$ cells.

95. Kupper, T. S. Immunologic targets in psoriasis. N. Engl. J. Med. 349, 1987-1990 (2003).

96. Cather, J. \& Menter, A. Novel therapies for psoriasis. Am. J. Clin. Dermatol. 3, 159-173 (2002).

97. Asadullah, K. et al. IL-10 is a key cytokine in psoriasis. Proof of principle by IL-10 therapy: a new therapeutic approach. J. Clin. Invest. 101, 783-794 (1998).

98. Trepicchio, W. L. et al. Interleukin-11 therapy selectively downregulates type I cytokine proinflammatory pathways in psoriasis lesions. J. Clin. Invest. 104, 1527-1537 (1999).

99. Ghoreschi, K. et al. Interleukin-4 therapy of psoriasis induces $T_{H} 2$ responses and improves human autoimmune disease. Nature Med. 9, 40-46 (2003).

100. Cather, J. C. \& Abramovits, W. Investigational therapies for psoriasis. J. Am. Acad. Dermatol. 49, S133-S138 (2003)

101. Williams, J. D. \& Griffiths, C. E. Cytokine blocking agents in dermatology. Clin. Exp. Dermatol. 27, 585-590 (2002).

102. Bhushan, M. et al. Anti-E-selectin is ineffective in the treatment of psoriasis: a randomized trial. Br. J. Dermatol. 146, 824-831 (2002)

103. Schon, M. P. et al. Efomycine M, a new specific inhibitor of selectin, impairs leukocyte adhesion and alleviates cutaneous inflammation. Nature Med. 8, 366-372 (2002).

104. Tofte, S. J. \& Hanifin, J. M. Current management and therapy of atopic dermatitis. J. Am. Acad. Dermatol. 44, S13-S16 (2001). 
105. Williams, H. C. Epidemiology of atopic dermatitis. Clin. Exp. Dermatol. 25, 522-529 (2000).

106. Hanifin, J. M. Epidemiology of atopic dermatitis. Monogr. Allergy 21, 116-131 (1987).

107. Engler, R. J., Kenner, J. \& Leung, D. Y. Smallpox vaccination: risk considerations for patients with atopic dermatitis. J. Allergy Clin. Immunol. 110, 357-365 (2002).

108. Sidbury, R. \& Hanifin, J. M. Old, new, and emerging therapies for atopic dermatitis. Dermatol. Clin. 18, 1-11 (2000).

109. Shum, K. W., Lawton, S., Williams, H. C., Docherty, G. \& Jones, J. The British Association of Dermatologists audit of atopic eczema management in secondary care. Phase 2 : audit of service process. Br. J. Dermatol. 142, 274-278 (2000).

110. Wuthrich, B. \& Schmid-Grendelmeier, P. The atopic eczema/dermatitis syndrome. Epidemiology, natural course, and immunology of the lgE-associated ('extrinsic') and the nonallergic ('intrinsic') AEDS. J. Investig. Allergol. Clin. Immunol. 13, 1-5 (2003).

111. Akdis, C. \& Akdis, M. Immunological differences between intrinsic and extrinsic types of atopic dermatitis. Clin. Exp. Allergy 33, 1618-1621 (2003).

112. Bohle, B et al. Long-lived T 2 clones specific for seasonal and perennial allergens can be detected in blood and skin by their TCR-hypervariable regions. J. Immunol. 160, 2022-2027 (1998).

113. Grewe, M. et al. A role for $T_{H} 1$ and $T_{4} 2$ cells in the immunopathogenesis of atopic dermatitis. Immunol. Today 19 359-361 (1998)

114. Ong, P. Y. et al. Endogenous antimicrobial peptides and skin infections in atopic dermatitis. N. Engl. J. Med. 347, 1151-1160 (2002).

115. Nomura, I. et al. Cytokine milieu of atopic dermatitis, as compared to psoriasis, skin prevents induction of innate immune response genes. J. Immunol. 171, 3262-3269 (2003).

116. Grabbe, S. \& Schwarz, T. Immunoregulatory mechanisms involved in elicitation of allergic contact hypersensitivity. Am. J. Contact Dermat. 7, 238-246 (1996).

117. Kimber, I. \& Dearman, R. J. Allergic contact dermatitis: the cellular effectors. Contact Dermatitis 46, 1-5 (2002)

118. Leung, D. Y. Molecular basis of allergic diseases. Mol. Genet. Metab. 63, 157-167 (1998)

119. Cavani, A. et al. Human CD4+ T lymphocytes with remarkable regulatory functions on dendritic cells and nickel-specific T 1 immune responses. J. Invest. Dermatol. 114, 295-302 (2000).

120. Aractingi, S. \& Chosidow, O. Cutaneous graft-versus-host disease. Arch. Dermatol. 134, 602-612 (1998).

121. Edelson, R. L. Cutaneous T cell lymphoma: the helping hand of dendritic cells. Ann. NY Acad. Sci. 941, 1-11 (2001).

122. Rook, A. H. et al. Pathogenesis of cutaneous T-cell lymphoma: implications for the use of recombinant cytokines and photopheresis. Clin. Exp. Immunol. 107 Suppl. 1, 16-20 (1997).

123. Yawalkar, N. et al. Profound loss of T cell receptor repertoire complexity in cutaneous T cell lymphoma. Blood 102, 4059-4066 (2003).

124. Kemp, E. H., Waterman, E. A. \& Weetman, A. P. Immunological pathomechanisms in vitiligo. Expert Rev. Mol. Med. 3, 1-22 (2001)

125. Ogg, G. S., Dunbar, R., Romero, P., Chen, J. L. \& Cerundolo, V. High frequency of skin-homing melanocytespecific cytotoxic T lymphocytes in autoimmune vitiligo. J. Exp. Med. 188, 1203-1208 (1998).

126. Clark, W. H., Jr, From, L., Bernardino, E. A. \& Mihm, M. C. The histogenesis and biologic behavior of primary human malignant melanomas of the skin. Cancer Res. 29 705-727 (1969).

127. Ruiter, D. J., Bhan, A. K., Harrist, T. J., Sober, A. J. \& Mihm, M. C., Jr. Major histocompatibility antigens and mononuclear inflammatory infiltrate in benign nevomelanocytic proliferations and malignant melanoma. J. Immunol. 129, 2808-2815 (1982).
128. Clark, W. H., Jr. et al. A study of tumor progression: the precursor lesions of superficial spreading and nodular melanoma. Hum. Pathol. 15, 1147-1165 (1984).

129. Ferradini, L. et al. Analysis of T cell receptor variability in tumor-infiltrating lymphocytes from a human regressive melanoma. Evidence for in situ T cell clonal expansion. J. Clin. Invest. 91, 1183-1190 (1993).

130. Mackensen, A. et al. Evidence for in situ amplification of cytotoxic T-lymphocytes with antitumor activity in a human regressive melanoma. Cancer Res. 53, 3569-3573 (1993).

131. Mackensen, A. et al. Direct evidence to support the immunosurveillance concept in a human regressive melanoma. J. Clin. Invest. 93, 1397-1402 (1994).

132. Salvi, S. et al. Overexpression of the T-cell receptor $\beta$-chain variable region TCRBV14 in HLA-A2-matched primary human melanomas. Cancer Res. 55, 3374-3379 (1995).

133. Clark, W. H., Jr. et al. Model predicting survival in stage melanoma based on tumor progression. J. Nat/ Cancer Inst. 81, 1893-1904 (1989).

134. Pastorfide, G. C. et al. Image analysis of stage 1 melanoma (1. 00-2. $50 \mathrm{~mm}$ ): lymphocytic infiltrates related to metastasis and survival. J. Cutan. Pathol. 19, 390-397 (1992).

135. Clemente, C. G. et al. Prognostic value of tumor infiltrating lymphocytes in the vertical growth phase of primary cutaneous melanoma. Cancer 77, 1303-1310 (1996).

136. Weber, L. W. et al. Tumor immunity and autoimmunity induced by immunization with homologous DNA. J. Clin. Invest. 102, 1258-1264 (1998).

137. Bendandi, M. et al. Complete molecular remissions induced by patient-specific vaccination plus granulocyte-monocyte colony-stimulating factor against lymphoma. Nature Med. 5, 1171-1177 (1999).

This study highlighted the capacity of tumour-specific vaccination to induce complete remissions and set the standards for future cancer vaccine trials.

138. Restifo, N. P. \& Rosenberg, S. A. Developing recombinant and synthetic vaccines for the treatment of melanoma. Curr. Opin. Oncol 11, 50-57 (1999).

139. Nair, S. K. et al. Induction of cytotoxic T cell responses and tumor immunity against unrelated tumors using telomerase reverse transcriptase RNA transfected dendritic cells. Nature Med. 6, 1011-1017 (2000).

140. Nestle, F. O., Banchereau, J. \& Hart, D. Dendritic cells: on the move from bench to bedside. Nature Med. 7, 761-765 (2001)

141. Jager, E., Jager, D. \& Knuth, A. Clinical cancer vaccine trials. Curr. Opin. Immunol. 14, 178-182 (2002).

142. Nestle, F. O. Vaccines and melanoma. Clin. Exp. Dermatol. 27, 597-601 (2002)

143. Dranoff, G. GM-CSF-secreting melanoma vaccines. Oncogene 22, 3188-3192 (2003).

144. Engleman, E. G. Dendritic cell-based cancer immunotherapy. Semin. Oncol. 30, 23-29 (2003).

145. Mackensen, A. et al. Homing of intravenously and intralymphatically injected human dendritic cells generated in vitro from $\mathrm{CD}_{3} 4^{+}$hematopoietic progenitor cells. Cancer Immunol. Immunother. 48, 118-122 (1999).

146. Onaitis, M., Kalady, M. F., Pruitt, S. \& Tyler, D. S. Dendritic cell gene therapy. Surg. Oncol. Clin. N. Am. 11, 645-660 (2002).

147. Gilliet, M. et al. Intranodal injection of semimature monocytederived dendritic cells induces $T$ helper type 1 responses to protein neoantigen. Blood 102, 36-42 (2003).

148. Touloukian, C. E. \& Rosenberg, S. A. A survey of treatments used in patients with metastatic melanoma: analysis of 189 patients referred to the National Cancer Institute. Cancer J. Sci. Am. 5, 269-274 (1999).

149. Robert, C. et al. Gene therapy to target dendritic cells from blood to lymph nodes. Gene Ther. 10, 1479-1486 (2003).

150. Dhodapkar, M. V. \& Steinman, R. M. Antigen-bearing immature dendritic cells induce peptide-specific $\mathrm{CD}^{+}$ regulatory T cells in vivo in humans. Blood 100, 174-177 (2002).

151. Henderson, D. A. Smallpox: clinical and epidemiologic features. Med. Health R. I. 85, 107-108 (2002).
152. McClain, D. J. et al. Immunologic responses to vaccinia vaccines administered by different parenteral routes. J. Infect. Dis. 175, 756-763 (1997).

This report confirmed the decades old clinical impression that scarification as a method of vaccinia-virus vaccination was superior to subcutaneous and intramuscular injection in the induction of vaccinia-virus-specific immune responses.

153. Goldstein, J. A., Neff, J. M., Lane, J. M. \& Koplan, J. P. Smallpox vaccination reactions, prophylaxis, and therapy of complications. Pediatrics 55, 342-347 (1975).

154. Leung, D. Y. \& Soter, N. A. Cellular and immunologic mechanisms in atopic dermatitis. J. Am. Acad. Dermatol. 44 S1-S12 (2001).

155. Jackson, R. J. et al. Expression of mouse interleukin-4 by a recombinant ectromelia virus suppresses cytolytic lymphocyte responses and overcomes genetic resistance to mousepox. J. Virol. 75, 1205-1210 (2001)

156. Ambach, A., Bonnekoh, B. \& Gollnick, H. Perforin hyperreleasability and depletion in cytotoxic $T$ cells from patients with exacerbated atopic dermatitis and asymptomatic rhinoconjunctivitis allergica. J. Allergy Clin. Immunol. 107, 878-886 (2001).

157. Hirata, T. et al. P-selectin glycoprotein ligand 1 (PSGL-1) is a physiological ligand for E-selectin in mediating Thelper 1 lymphocyte migration. J. Exp. Med. 192, 1669-1676 (2000)

158. Abernathy-Carver, K., Sampson, H., Picker, L. \& Leung, D. Milk-induced eczema is associated with the expansion of T cells expressing cutaneous lymphocyte antigen. J. Clin. Invest. 95, 913-918 (1995).

159. Tanaka, T. et al. Interleukin-18 is elevated in the sera from patients with atopic dermatitis and from atopic dermatitis model mice, NC/Nga. Int. Arch. Allergy Immunol. 125 236-240 (2001).

160. Girolomoni, G. \& Pastore, S. The role of keratinocytes in the pathogenesis of atopic dermatitis. J. Am. Acad. Dermatol. 45, S25-S28 (2001)

161. Giustizieri, M. L. et al. Keratinocytes from patients with atopic dermatitis and psoriasis show a distinct chemokine production profile in response to $\mathrm{T}$ cellderived cytokines. J. Allergy Clin. Immunol. 107, 871-877 (2001)

162. Pastore, S., Corinti, S., La Placa, M., Didona, B. \& Girolomoni, G. Interferon- $\gamma$ promotes exaggerated cytokine production in keratinocytes cultured from patients with atopic dermatitis. J. Allergy Clin. Immunol. 101, 538-544 (1998).

Acknowledgements

This work is supported by the National Institutes of Health.

Competing interests statement

The authors declare that they have no competing financial interests.

\section{(2)) Online links}

\section{DATABASES}

The following terms in this article are linked online to: LocusLink: http://www.ncbi.nlm.nih.gov/LocusLink/ CCL17 | CCL22 | CCL27 | CCR4 | CCR6 | CCR7 | CCR10 | CD62L | CD80 | CD86 | CTLA4 | CXCL9 | CXCL10 | CXCL11 | CXCR3 | E-selectin | GM-CSF | ICAM1 | IFN- $\gamma|| \mathrm{LL}-1 \alpha|| \mathrm{L}-1 \beta$ | IL-4 | IL-5 | IL-6 | IL-10 | IL-13 | LFA1 | P-selectin | TNF VCAM1

\section{FURTHER INFORMATION}

Harvard Skin Research Center:

http://dermatology.bwh.harvard.edu

Brigham and Women's Hospital Dermatology Clinic:

http://www.brighamandwomens.org/dermatology/

Access to this interactive links box is free online. 